Communication

\title{
Characteristics of Thermosetting Polymer Nanocomposites: Siloxane-Imide-Containing Benzoxazine with Silsesquioxane Epoxy Resins
}

\author{
Chih-Hao Lin ${ }^{1}{ }^{\mathbb{B}}$, Wen-Bin Chen ${ }^{2}$, Wha-Tzong Whang ${ }^{1}$ and Chun-Hua Chen ${ }^{1, *}$ \\ 1 Department of Materials Science and Engineering, National Chiao Tung University, \\ Hsinchu 300093, Taiwan; howardlin@itri.org.tw (C.-H.L.); wtwhang@mail.nctu.edu.tw (W.-T.W.) \\ 2 Material and Chemical Research Laboratories, Industrial Technology Research Institute, Chutung, \\ Hsinchu 31040, Taiwan; abin@itri.org.tw \\ * Correspondence: chunhuachen@mail.nctu.edu.tw; Tel.: +886-3513-1287
}

Received: 16 September 2020; Accepted: 26 October 2020; Published: 28 October 2020

\begin{abstract}
A series of innovative thermosetting polymer nanocomposites comprising of polysiloxane-imide-containing benzoxazine (PSiBZ) as the matrix and double-decker silsesquioxane (DDSQ) epoxy or polyhedral oligomeric silsesquioxane (POSS) epoxy were prepared for improving thermosetting performance. Thermomechanical and dynamic mechanical characterizations indicated that both DDSQ and POSS could effectively lower the coefficient of thermal expansion by up to approximately $34 \%$ and considerably increase the storage modulus (up to 183\%). Therefore, DDSQ and POSS are promising materials for low-stress encapsulation for electronic packaging applications.
\end{abstract}

Keywords: polysiloxane-imide-containing benzoxazine; polyhedral oligomeric silsesquioxane epoxy; double-decker silsesquioxane epoxy; polymer nanocomposite

\section{Introduction}

Compared with pristine polymer nanocomposites, hybrid organic-inorganic nanocomposites comprising of functional polymers as the matrix and nanoscale inorganic constituents have attracted greater interest in both academia and industry because of their tunable and generally more favorable thermal, mechanical, electrical, and barrier properties [1-3]. Upgrading current thermosetting polymers has become critical because of their utilization in various applications. Such as fuel cells [4], catalysis [5], membranes [6], $\mathrm{CO}_{2}$ adsorption [7], metal uptake [8], coatings [9], thermal insulation [10], and super capacitor [11]. Studies using nanoparticles for modifying thermosetting polymers have revealed the feasibility of hybrid strategies [12-14].

Polybenzoxazine (PBZ) is considered a high-performance thermosetting resin because of its excellent thermal stability, high modulus, low water absorption, low surface free energy, and near-zero shrinkage upon curing [15-17]. Those properties are superior to some other thermosetting polymers. Crucially, PBZ requires simple procedures of thermal activated ring opening polymerization without the need for catalysts, and do not form byproducts. The low surface free energy property would allow it to have many potential applications as mold release material, lithographic patterning, and super hydrophobic surface material [18-24]. However, high curing temperatures and poor mechanical properties (brittleness) severely limit PBZ applications. Modification of benzoxazine monomer structures, blending with other polymers, and addition of nanoscale fillers or fibers are the currently major approaches to overcoming the drawbacks of PBZ [25-28]. Chen et al. demonstrated that siloxane-imine-containing benzoxazine (SiBZ) monomers $[29,30]$ could be used to synthesize PBZ with improved flexibility and weather resistance and reduced surface free energy. However, the conjunction 
of the siloxane segment and benzoxazine can directly increase the coefficient of thermal expansion (CTE) and thus pose a problem of dimensional instability.

Silsesquioxane, with a general formula of $\left(\mathrm{RSiO}_{3 / 2}\right)_{\mathrm{n}}$ is a representative organic-inorganic compound. Cubic polyhedral oligomeric silsesquioxane (POSS), a silsesquioxane derivative, consists of an inorganic silsesquioxane core with a pore diameter of $0.3-0.4 \mathrm{~nm}$ and organic functional groups at the vertex of the cubic silsesquioxane frame. The introduction of organic substituents, such as alkyl, aryl, epoxy, or amine groups, into POSS has improved compatibility between the POSS molecule and polymer matrices [31-35]. Another silsesquioxane derivative, double-decker silsesquioxane (DDSQ) contains two substituents, such as epoxy or allyl groups, in diagonal positions [36-39]. Incorporation of POSS or DDSQ into polymer matrices is an effective strategy to enhance thermal stability and mechanical and dielectric properties $[40,41]$.

Regarding the enhancement of the dimensional stability, although several studies have introduced cubic POSS to various polymer matrices, the resulting CTEs are not satisfactory. For instance, the use of POSS considerably reduced the CTE of a polyimide (PI) matrix [42]. By contrast, the presence of the octa-functionalized POSS epoxy in a thermosetting epoxy/HHPA matrix exhibited less influence on the CTE, which was attributed to the flexible organic tethers around the POSS cage forming a soft interphase [43].

Previous research also incorporate POSS or DDSQ with conventional PBZ and demonstrate the enhancement of thermal oxidation stability, mechanical properties [44-46]; however, a high rigid structure of PBZ, POSS, or DDSQ make the nanocomposites become brittle. In this study, we focused on the improvement of the dimensional stability of more flexible polysiloxane-imide-containing benzoxazine (PSiBZ). Two potential candidates, namely, octa-functionalized POSS epoxy and 3,13-diglycidyloxypropyloctaphenyl DDSQ epoxy, were selected as the organic-inorganic hybrid dopants for the PSiBZ matrix because of their caged silsesquioxane structures and chemical affinities with the matrix. In the molecular structure, DDSQ has larger cage dimensions than cubic POSS and thus is expected to provide desired thermal dimension stability (reduced CTEs) for organic-inorganic nanocomposite materials. The design concept is shown in Scheme 1.

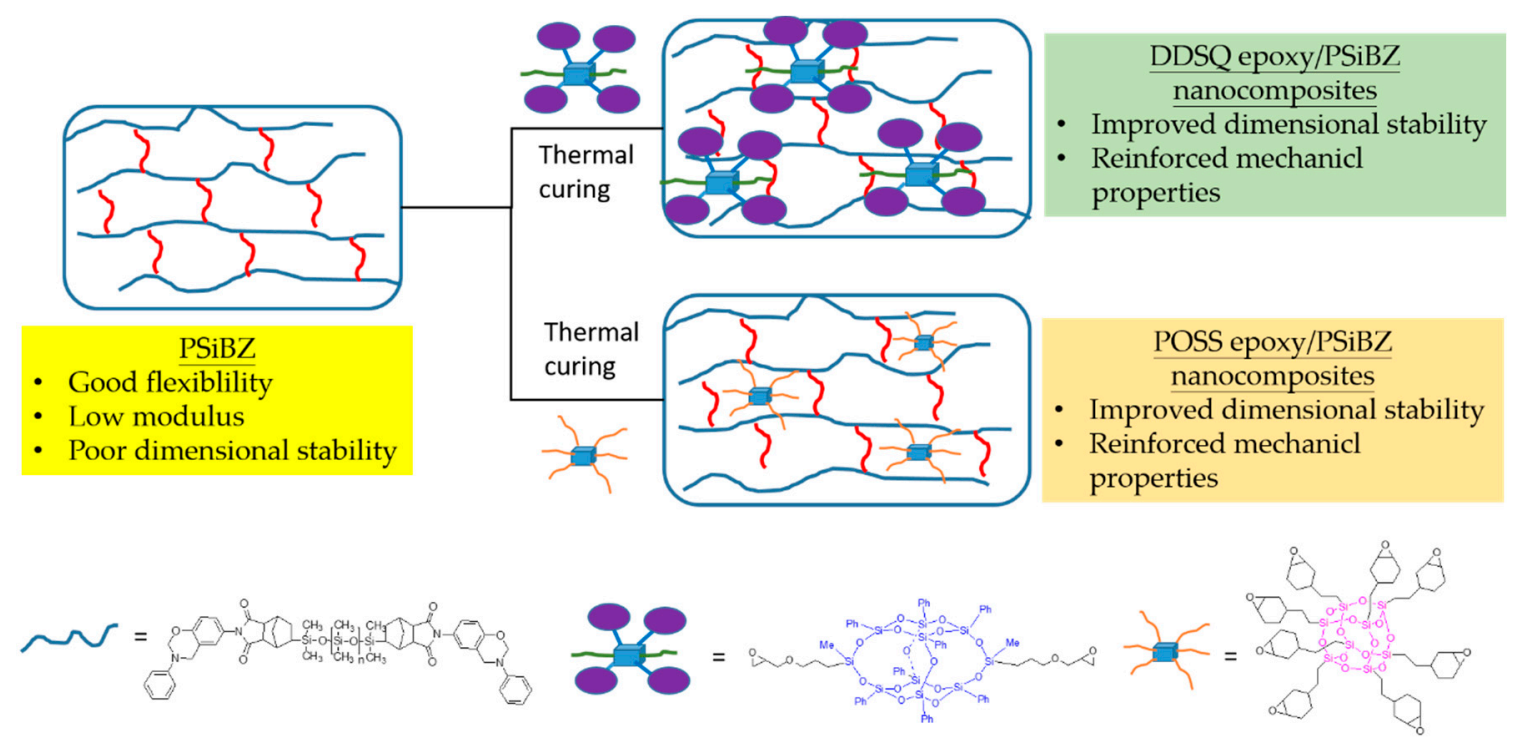

Scheme 1. The design concept of (a) DDSQ epoxy/PSiBZ and (b) POSS epoxy/PSiBZ nanocomposites.

\section{Materials and Methods}

\subsection{Materials}

Phenyltrimethoxysilane (97\%), dichloromethylsilane (97\%), triethylamine (99.5\%), isopropyl alcohol (99.5\%), and allyl glycidyl ether (99\%) were purchased from Sigma-Aldrich (St. Louis, MO, USA). 
Sodium hydroxide was purchased from UniRegion Bio-Tech (Hsinchu, Taiwan). Tetrahydrofuran (95\%) was purchased from Fisher Chemical (Pittsburgh, PA, USA). Toluene (99.5\%) was obtained from J.T. Baker (Phillipsburg, NJ, USA). Tris(dibutylsulfide)rhodium trichloride was obtained from Gelest (Morrisville, PA, USA). N,N-dioctadecylmethylamine was supplied by Fluka (Tokyo, Japan). Activated charcoal powder was obtained from Showa (Saitama, Japan). Siloxane-imide-containing benzoxazine monomer (SiBZ) was provided by Industrial Technology Research Institute (Hsinchu, Taiwan). Octa-functionalized POSS epoxy $(70 \mathrm{wt} \%)$ in cyclopentanone was purchased from Hybrid Plastics (Hattiesburg, MS, USA). DDSQ epoxy was prepared with reference to previous literature [38,40]. The following is the structure of the as-synthesized DDSQ epoxy was confirmed through ${ }^{1} \mathrm{H}$ nuclear magnetic resonance (NMR): $0.31\left(\mathrm{~s}, \mathrm{Si}-\mathrm{CH}_{3}\right), 0.74\left(\mathrm{t}, \mathrm{Si}-\mathrm{CH}_{2}-\right), 1.70\left(\mathrm{~m}, \mathrm{Si}-\mathrm{CH}_{2}-\mathrm{CH}_{2}-\right), 2.45$ and 2.67 (m,-O-CH $2_{2-}^{-}$epoxide), 2.98 (m, -O-CH-, epoxide), 3.17 and 3.45 (m, Si- $\left(\mathrm{CH}_{2}\right)_{3}-\mathrm{O}-\mathrm{CH}_{2}-\mathrm{l}$, and $3.34 \mathrm{ppm}(\mathrm{m}$, $\left.\mathrm{Si}-\mathrm{CH}_{2}-\mathrm{CH}_{2}-\mathrm{CH}_{2}-\mathrm{O}-\right)$. The chemical structures of the SiBZ monomer, DDSQ epoxy, and POSS epoxy are displayed in Figure 1a-c, respectively.

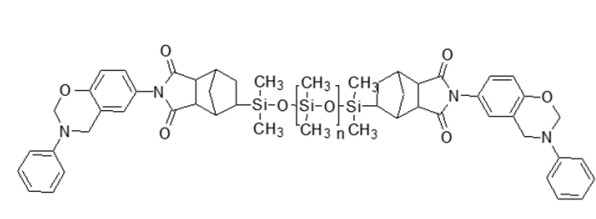

(a)

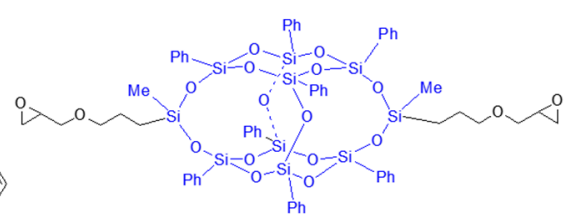

(b)

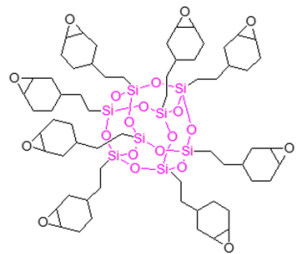

(c)

Figure 1. Chemical structure of (a) siloxane-imide-containing benzoxazine monomer (SiBZ), (b) double-decker silsesquioxane (DDSQ) epoxy, and (c) polyhedral oligomeric silsesquioxane (POSS) epoxy.

\subsection{Preparation of DDSQ Epoxy/PSiBZ and POSS Epoxy/PSiBZ Nanocomposites}

The weight ratios of the prepared DDSQ epoxy/PSiBZ and POSS epoxy/PSiBZ nanocomposites are displayed in Table 1. A mixture of the POSS or DDSQ epoxy and SiBZ monomers was dissolved in toluene to form a homogeneous solution with a solid content of $50 \mathrm{wt} \%$. The mixture was then poured into an aluminum pan to remove the solvent through heating at $100{ }^{\circ} \mathrm{C}$ for $5 \mathrm{~h}$. According to the results of differential scanning calorimetry (DSC) analysis, pure SiBZ and DDSQ epoxy/SiBZ were cured at 200 and $230{ }^{\circ} \mathrm{C}$ for $2 \mathrm{~h}$. POSS epoxy/SiBZ were cured at $200{ }^{\circ} \mathrm{C}$ for $2 \mathrm{~h}$ and $230{ }^{\circ} \mathrm{C}$ for $6 \mathrm{~h}$.

Table 1. Composition of double-decker silsesquioxane (DDSQ) epoxy/ polysiloxane-imide-containing benzoxazine (PSiBZ) and polyhedral oligomeric silsesquioxane (POSS) epoxy/PSiBZ nanocomposites.

\begin{tabular}{cccc}
\hline Sample & SiBZ * & DDSQ Epoxy & POSS Epoxy \\
\hline PSiBZ & $100 w t \%$ & - & - \\
$20 w t \%$ DDSQ epoxy/PSiBZ & $80 w t \%$ & $20 w t \%$ & - \\
$40 w t \%$ DDSQ epoxy/PSiBZ & $60 w t \%$ & $40 w t \%$ & - \\
$20 w t \%$ POSS epoxy/PSiBZ & $80 w t \%$ & - & $20 w t \%$ \\
$40 w t \%$ POSS epoxy/PSiBZ & $60 w t \%$ & - & $40 \mathrm{wt} \%$ \\
\hline
\end{tabular}

* Siloxane-imide-containing benzoxazine monomer.

\subsection{Instrumentation}

Proton nuclear magnetic resonance $\left({ }^{1} \mathrm{H}-\mathrm{NMR}\right)$ analysis was performed using an NMR spectrometer (Varian $500 \mathrm{MHz}$; Agilent, Santa Clara, CA, USA) with $\mathrm{CDCl}_{3}$ as the solvent and tetramethylsilane (TMS) as a reference. Differential scanning calorimetry (DSC Q10; TA Instruments, New Castle, DE, USA) was conducted under a nitrogen atmosphere. Approximately $10 \mathrm{mg}$ of the testing sample was sealed in an aluminum pan. The samples were heated from 40 to $250{ }^{\circ} \mathrm{C}$ at a heating rate of $10{ }^{\circ} \mathrm{C} / \mathrm{min}$. The onset temperature, peak temperature, and enthalpy of the exothermic peak of the cured compositions were recorded. Thermal degradation properties were measured using a thermogravimetric analyzer (TGA, Q500; 
TA Instruments, New Castle, DE, USA) from 30 to $800^{\circ} \mathrm{C}$ at a heating rate of $10^{\circ} \mathrm{C} / \mathrm{min}$. Dynamic mechanical analysis (DMA, Q800; TA Instruments, New Castle, DE, USA) was performed at a heating rate of $5^{\circ} \mathrm{C} / \mathrm{min}$ from -80 to $280^{\circ} \mathrm{C}$ with a fixed frequency of $1 \mathrm{~Hz}$ in the single cantilever mode. The dimensions of the test species were $17.5 \mathrm{~mm}(\mathrm{~L}) \times 10.0 \mathrm{~mm}(\mathrm{~W}) \times 0.5 \mathrm{~mm}(\mathrm{~T})$. Thermomechanical analysis (TMA, Q400; TA Instruments, New Castle, DE, USA) was conducted at a heating rate of $10^{\circ} \mathrm{C} / \mathrm{min}$ from 30 to $250{ }^{\circ} \mathrm{C}$, and a force of $0.05 \mathrm{~N}$ was applied.

\section{Results and Discussion}

\subsection{Curing Behavior of DDSQ Epoxy/PSiBZ and POSS Epoxy/PSiBZ Nanocomposites}

The curing reactions of the pure PSiBZ, DDSQ epoxy/PSiBZ nanocomposites and POSS epoxy/PSiBZ nanocomposites are illustrated in Scheme 2. The SiBZ monomer can self-cure through thermal activated ring-opening polymerization and co-cure with DDSQ or POSS epoxy to form DDSQ epoxy/PSiBZ and POSS epoxy/PSiBZ thermosetting nanocomposites under a high temperature condition [47].

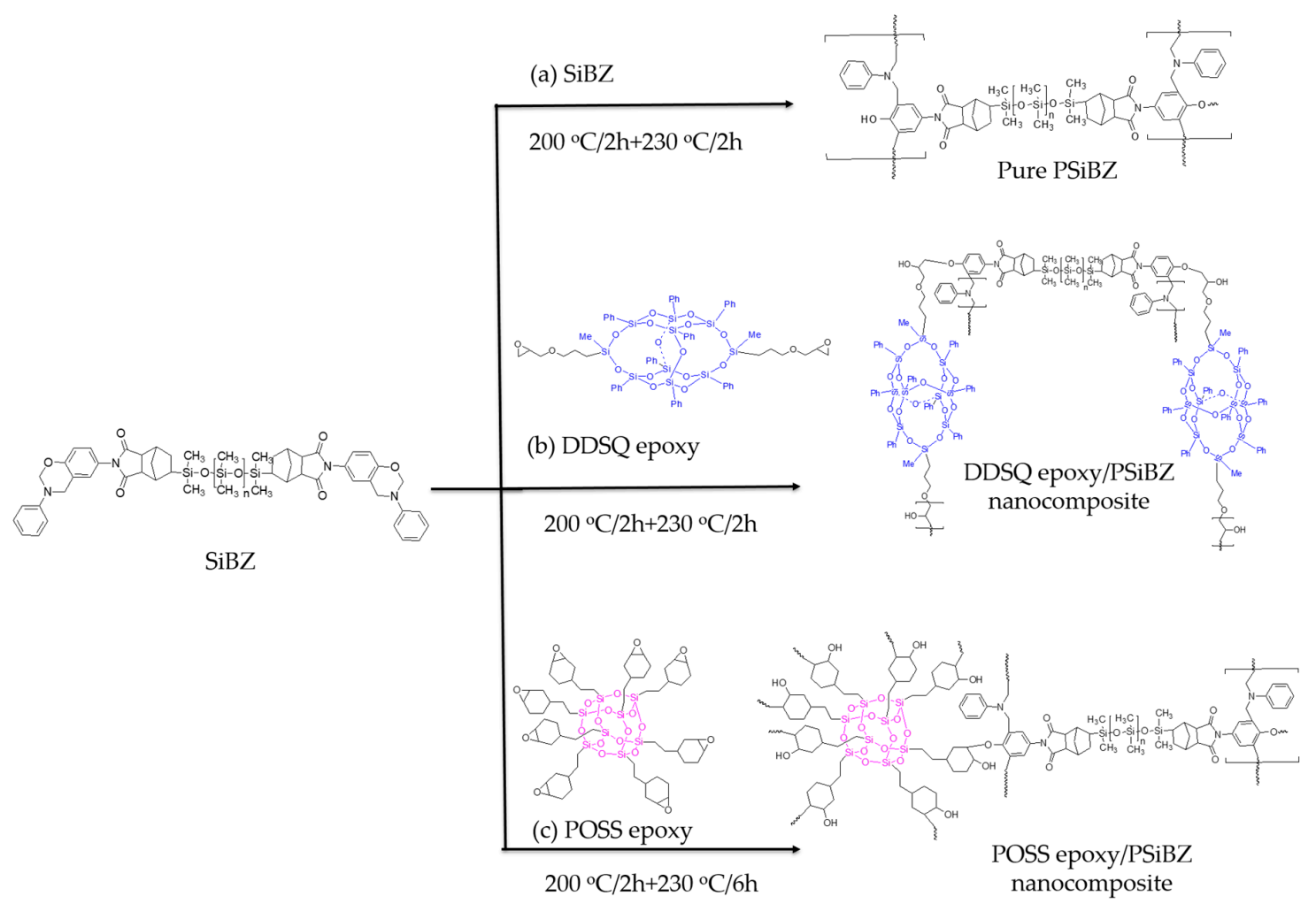

Scheme 2. Cross-linking structure of (a) pure polysiloxane-imide-containing benzoxazine (PSiBZ),

(b) DDSQ epoxy/PSiBZ, and (c) POSS epoxy/PSiBZ nanocomposites.

The DSC thermograms of the pure PSiBZ, the DDSQ epoxy/PSiBZ, and POSS epoxy/PSiBZ nanocomposites are shown the exothermic curve and displayed in Figure 2 and the summary of the curing characteristics are listed in Table 2. In the DDSQ epoxy/PSiBZ system, both the exothermic onset and peak temperatures increased with the percentage by weight of DDSQ epoxy. A similar tendency was observed for POSS epoxy/PSiBZ; however, the steric hindrance of the eight epoxy group in the vicinity position of the POSS core was higher than two epoxy group in diagonal position of DDSQ core, which resulted in the exothermic onset and exothermic with a maximum temperature of POSS epoxy/PSiBZ higher than those of DDSQ epoxy/PSiBZ and thus the curing time at $230{ }^{\circ} \mathrm{C}$ of POSS epoxy/PSiBZ was set longer than DDSQ epoxy/PSiBZ to ensure the cured reaction completely. 

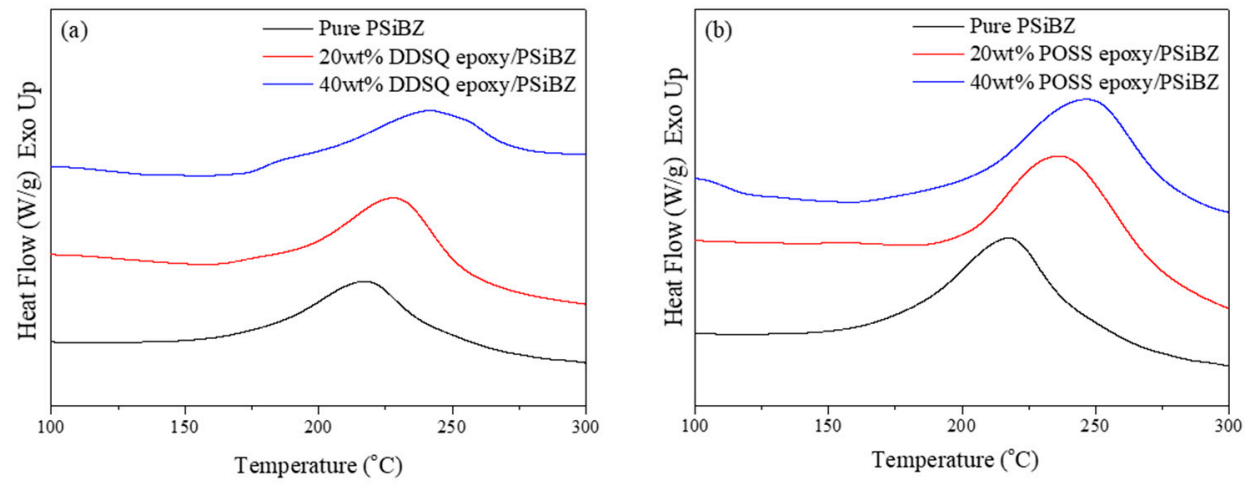

Figure 2. Exothermic curves of (a) DDSQ epoxy/PSiBZ and (b) POSS epoxy/PSiBZ nanocomposites.

Table 2. Curing characteristics of pure PSiBZ, DDSQ epoxy/PSiBZ nanocomposites, and POSS epoxy/PSiBZ nanocomposites.

\begin{tabular}{ccc}
\hline Sample & $\mathbf{T}_{\text {onset }}\left({ }^{\circ} \mathbf{C}\right)$ & $\mathbf{T}_{\max }\left({ }^{\circ} \mathbf{C}\right)$ \\
\hline Pure PSiBZ & 173 & 218 \\
$20 \mathrm{wt} \%$ DDSQ epoxy/PSiBZ & 186 & 229 \\
$40 \mathrm{wt} \%$ DDSQ epoxy/PSiBZ & 190 & 241 \\
$20 \mathrm{wt} \%$ POSS epoxy/PSiBZ & 198 & 238 \\
$40 \mathrm{wt} \%$ POSS epoxy/PSiBZ & 199 & 248 \\
\hline
\end{tabular}

The chain mobility of PSiBZ was restricted by the incorporation of the rigid DDSQ or POSS cage into its structure; therefore, the onset and peak temperatures increased with the DDSQ or POSS content. Liu et al. also found a similar curing phenomenon in a PBZ-DDSQ copolymer. The onset and peak temperatures of the PBZ-DDSQ copolymer increased with the DDSQ content [44].

\subsection{Thermal Stability of DDSQ Epoxy/PSiBZ and POSS Epoxy/PSiBZ Nanocomposites}

The thermal stability of the pure PSiBZ, the DDSQ epoxy/PSiBZ nanocomposites and the POSS epoxy/PSiBZ nanocomposites was analyzed by TGA under air atmosphere as displayed in Figure 3a,b. The found $5 \%$ mass loss temperature $\left(T_{\mathrm{d} 5 \%}\right)$ was $419^{\circ} \mathrm{C}$ for the pure PSiBZ and slightly decreased to $413{ }^{\circ} \mathrm{C}$ and $410{ }^{\circ} \mathrm{C}$ for $20 \mathrm{wt} \%$ and $40 \mathrm{wt} \%$ DDSQ epoxy/PSiBZ, respectively. The decrease in $T_{\mathrm{d} 5 \%}$ should originate from the reacted two epoxy groups in the DDSQ Epoxy/PSiBZ nanocomposites. In the case of the POSS epoxy/PSiBZ nanocomposites, $T_{\mathrm{d} 5 \%}$ for $20 \mathrm{wt} \%$ and $40 \mathrm{wt} \%$ POSS epoxy/PSiBZ was $392{ }^{\circ} \mathrm{C}$ and $396{ }^{\circ} \mathrm{C}$, respectively, reasonably due to the presence of eight reacted epoxy groups of POSS with PSiBZ, leading to a lower thermal stability than the DDSQ epoxy/PSiBZ nanocomposites. The char yield of the DDSQ epoxy/PSiBZ and POSS epoxy/PSiBZ nanocomposites also increased with the increase of the DDSQ or POSS. As a result, the DDSQ epoxy/PSiBZ nanocomposites exhibited better thermal stability than the POSS epoxy/PSiBZ nanocomposites.

\subsection{Dynamic Mechanical Properties of DDSQ Epoxy/PSiBZ and POSS Epoxy/PSiBZ Nanocomposites}

The dynamic mechanical properties of the DDSQ epoxy/PSiBZ and POSS epoxy/PSiBZ nanocomposites from -100 to $280^{\circ} \mathrm{C}$ were characterized through DMA. The storage modulus and $\tan \delta$ of the DDSQ epoxy/PSiBZ and POSS epoxy/PSiBZ nanocomposites are presented in Figure 4 and Table 3. The storage modulus of pure PSiBZ was $960 \mathrm{MPa}$ at $25^{\circ} \mathrm{C}$. After 20 and $40 \mathrm{wt} \%$ DDSQ epoxy was added, the storage modulus increased to 1506 and $1516 \mathrm{MPa}$, respectively. In the $40 \mathrm{wt} \%$ POSS epoxy/PSiBZ, a higher storage modulus of $1753 \mathrm{MPa}$ was obtained. The increases were approximately $158 \%$ and $183 \%$ for DDSQ and POSS, respectively, indicating superior reinforcement with POSS. 

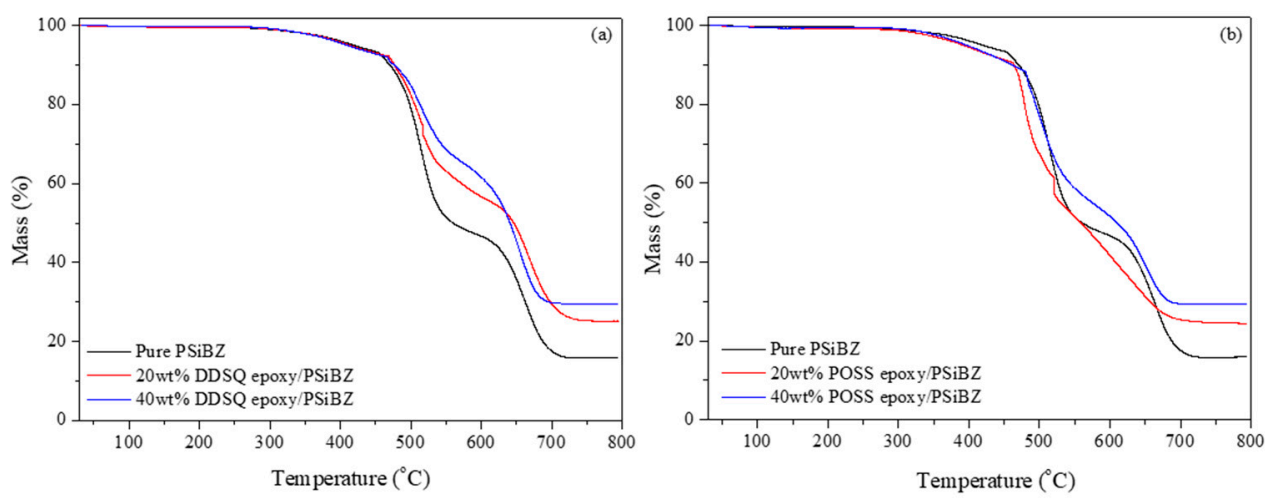

Figure 3. TGA thermograms of (a) DDSQ/PSiBZ nanocomposites and (b) POSS epoxy/ PSiBZ nanocomposites.
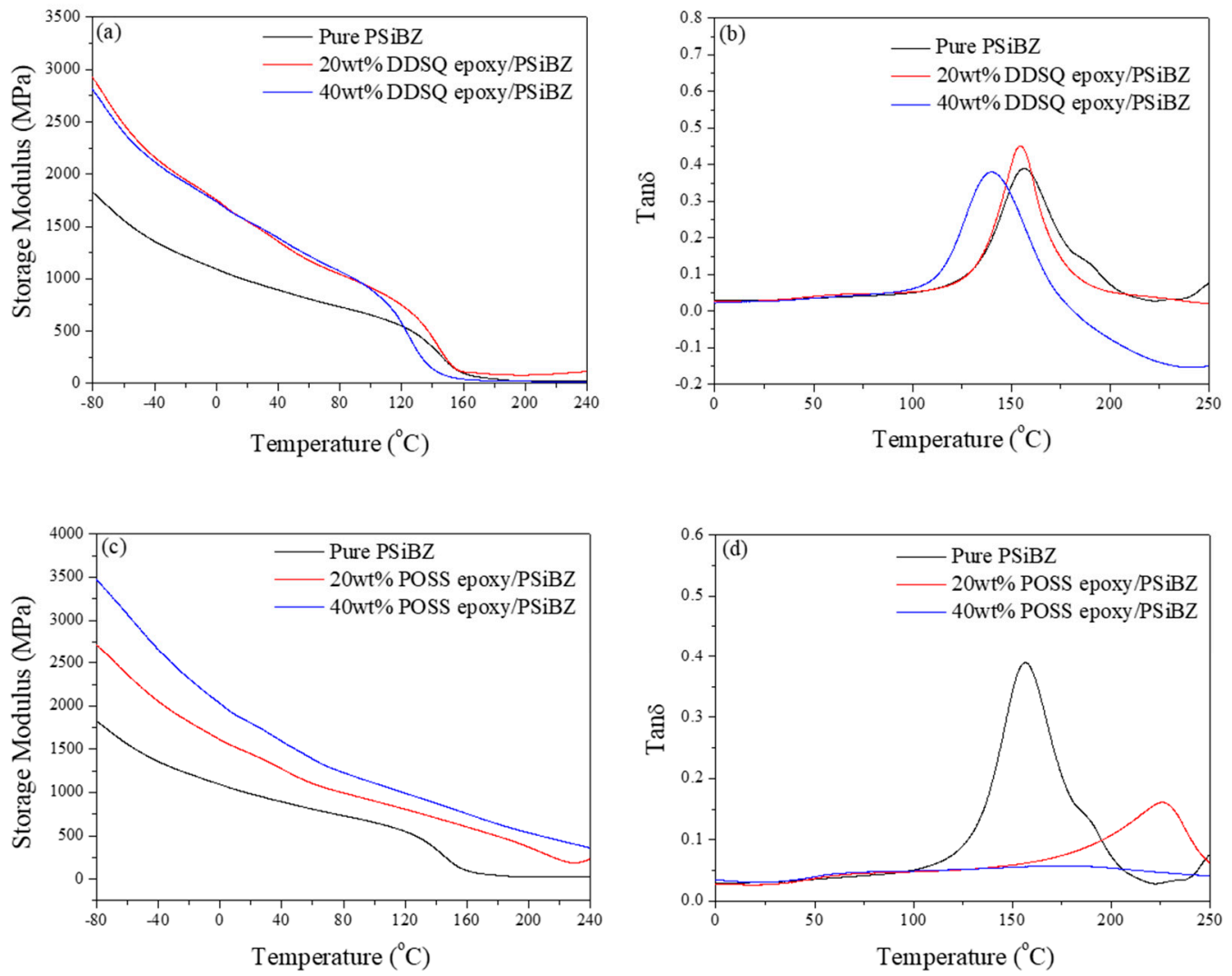

Figure 4. (a) Storage modulus and (b) $\tan \delta$ of DDSQ epoxy/PSiBZ nanocomposites as functions of temperature. (c) Storage modulus and (d) $\tan \delta$ of the POSS epoxy/PSiBZ nanocomposites as functions of temperature.

Table 3. Storage modulus and tan $\delta$ of DDSQ epoxy/PSiBZ and POSS epoxy/PSiBZ nanocomposites.

\begin{tabular}{ccc}
\hline Sample & Storage Modulus (MPa) $@ 25{ }^{\circ} \mathbf{C}$ & $\boldsymbol{T}_{\mathbf{g}}\left({ }^{\circ} \mathbf{C}\right)$ \\
\hline Pure PSiBZ & 960 & 157 \\
$20 \mathrm{wt} \%$ DDSQ epoxy/PSiBZ & 1506 & 155 \\
$40 \mathrm{wt} \%$ DDSQ epoxy/PSiBZ & 1516 & 140 \\
$20 \mathrm{wt} \%$ POSS epoxy/PSiBZ & 1407 & 226 \\
$40 \mathrm{wt} \%$ POSS epoxy/PSiBZ & 1753 & not obvious \\
\hline
\end{tabular}

The peak temperature from the tan $\delta$ curves of the DDSQ/PSiBZ nanocomposites revealed that the addition of 20 and $40 \mathrm{wt} \%$ of DDSQ lowered $T_{\mathrm{g}}$ from the $157^{\circ} \mathrm{C}$ of pure PSiBZ to 155 and $140{ }^{\circ} \mathrm{C}$, 
respectively. The eight bulky phenyl groups of the DDSQ epoxy disturbed the chain stack to increase larger free volume in the cross-linked structure and thus reduce the $T_{\mathrm{g}}$ [44]. By contrast, the addition of $20 \mathrm{wt} \%$ POSS epoxy resulted in a higher $T_{\mathrm{g}}$ of $226^{\circ} \mathrm{C}$. Notably, $T_{\mathrm{g}}$ becomes not obvious when the POSS epoxy content was $40 \mathrm{wt} \%$. The increased $T_{\mathrm{g}}$ can be attributed to the increased cross-linking caused by the presence of eight epoxy groups of POSS. Furthermore, at $40 \mathrm{wt} \%$ POSS epoxy, the apparent nano effect caused by strong interaction between nanoscale POSS epoxy and PSiBZ was found; consequently, $T_{\mathrm{g}}$ became not obvious. Similar nano effect phenomena have been previously observed $[48,49]$.

There are two major factors that led to the reinforcement of the DDSQ/PSiBZ and POSS/PSiBZ nanocomposites: (i) the rigidity of DDSQ and POSS and (ii) the $T_{\mathrm{g}}$ (directly related to the crosslinking density) of the DDSQ/PSiBZ and POSS/PSiBZ nanocomposites networks. In the case of DDSQ/PSiBZ nanocomposites, the storage modulus increased with increasing the DDSQ content due to the rigidity of DDSQ; however, the increased DDSQ simultaneously resulted in a lower $T_{\mathrm{g}}$, which would lead to the decrease of modules because of the decreased crosslinking density. The very close modulus found from the specimen of the 20 or $40 \mathrm{wt} \%$ of DDSQ epoxies could thus be considered as the competition of these two factors. On the other hand, in the POSS/PSiBZ system, both of the rigidity and $T_{\mathrm{g}}$ increase with the increase of the POSS epoxy. The eight epoxy groups in POSS could provide more crosslinking points in the POSS/PSiBZ network. As a consequence, the superior reinforcement effect could be obtained for the POSS/PSiBZ nanocomposites.

\subsection{Thermomechanical Properties of DDSQ Epoxy/PSiBZ and POSS Epoxy/PSiBZ Nanocomposites}

The CTEs of the DDSQ epoxy/PSiBZ and POSS epoxy/PSiBZ nanocomposites were investigated through TMA and compared with that of pure PSiBZ. Figure 5 illustrates the dimensional changes and CTEs of the pure PSiBZ, DDSQ epoxy/PSiBZ nanocomposites, and POSS epoxy/PSiBZ nanocomposites below the glass transition temperature $\left(T_{\mathrm{g}}\right)$. Figure $5 \mathrm{a}$ revealed that CTE 1 (below $T_{\mathrm{g}}$ at a temperature range of $40-75^{\circ} \mathrm{C}$ ) considerably decreased with an increase in DDSQ content. From 0 to $40 \mathrm{wt} \%$ of DDSQ, the decreases in CTE 1 were approximately $34 \%$. Notably, unlike the DDSQ epoxy system, the POSS epoxy/PSiBZ nanocomposites show the estimated changes in CTE 1 were approximately $14 \%$ (Figure $5 b$ ). The present results indicate that as the temperature decreased below $T_{\mathrm{g}}$, the molecules lose energy under the glassy state, only short-range molecular movement occurred, and the larger core dimension and the phenyl substituents at the vertex of the DDSQ frame efficiently restricted the chain mobility of PSiBZ. Thus, noticeable variation was observed in CTE 1. The results indicate that both adding $40 \mathrm{wt} \%$ DDSQ epoxy and POSS epoxy demonstrated the significant CTE 1 reduced the effect of PSiBZ; furthermore, a DDSQ epoxy exhibited more of a CTE 1 reduce effect than the POSS epoxy.
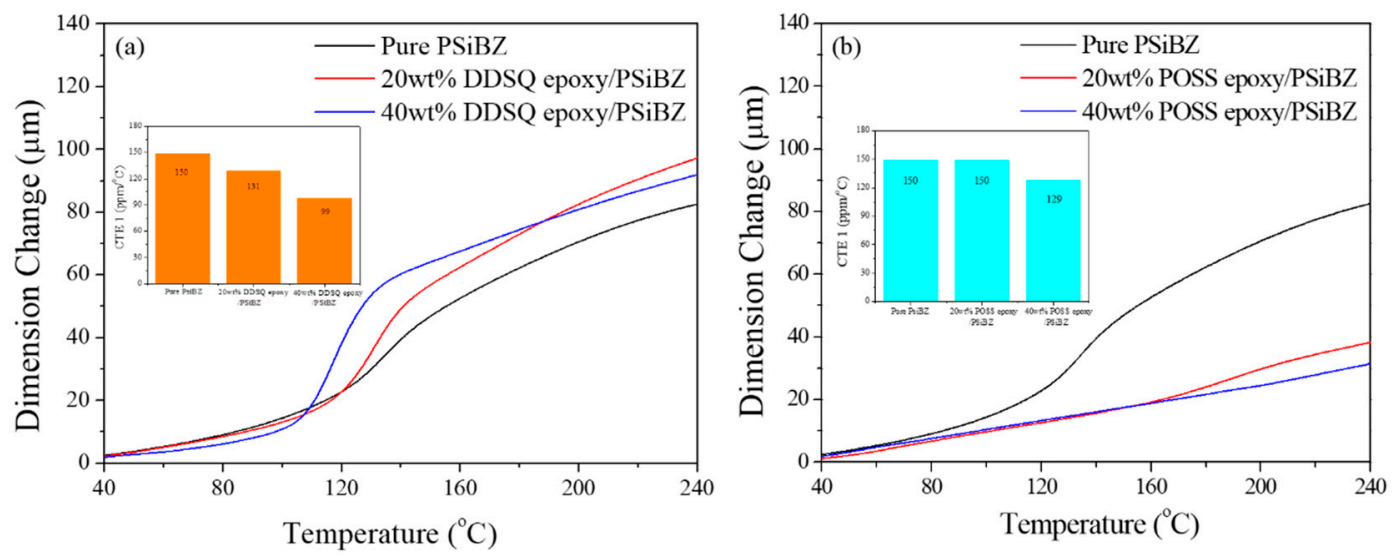

Figure 5. (a) Dimension change and coefficients of thermal expansion (CTEs) of the DDSQ epoxy/PSiBZ nanocomposites and (b) dimension change and CTEs of the POSS epoxy/PSiBZ epoxy nanocomposites. 


\section{Conclusions}

In this study, DDSQ epoxy and POSS epoxy were added to PSiBZ to achieve superior thermomechanical and dynamic mechanical properties. The addition of $40 \mathrm{wt} \%$ DDSQ epoxy resulted in a 34\% reduction in CTE 1 and 158\% increase in the storage modulus. The introduction of the $40 \mathrm{wt} \%$ POSS epoxy increased the storage modulus by $183 \%$. This study not only serves as proof of the design concept but also experimentally demonstrated the potential of the DDSQ and POSS epoxy as functional additives for PSiBZ for lowering the CTE while enhancing the thermomechanical properties.

Author Contributions: C.-H.L. conceived the original concept and conducted experiments and the investigation as well as wrote the manuscript. W.-B.C. provided SiBZ monomer. W.-T.W. and C.-H.C. directed and revised the manuscript. All authors have read and agreed to the published version of the manuscript.

Funding: This research received no external funding.

Acknowledgments: The authors would like to express their appreciation for the technical support from Material and Chemical Research Laboratories, ITRI.

Conflicts of Interest: The authors declare no conflict of interest.

\section{References}

1. Saegusa, T.; Chujo, Y. An Organic/Inorganic Hybrid Polymer. J. Marcromol. Sci. A Chem. 1990, 27, 1603-1612. [CrossRef]

2. Liu, H.; Zheng, W.; Zheng, S. Montmorillonite intercalated by ammonium of octaaminopropyl polyhedral oligomeric silsesquioxane and its nanocomposites with epoxy resin. Polymer 2005, 46, 157-165. [CrossRef]

3. Naka, K.; Irie, Y. Synthesis of single component element-block materials based on siloxane-based cage frameworks. Polym. Int. 2017, 66, 187-194. [CrossRef]

4. Kim, S.K.; Choi, S.W.; Jeon, W.S.; Park, J.O.; Ko, T.; Chang, H.; Lee, J.C. Cross-Linked Benzoxazine-Benzimidazole Copolymer Electrolyte Membranes for Fuel Cells at Elevated Temperature. Macromolecules 2012, 45, 1438-1446. [CrossRef]

5. Zhang, K.; Liu, Y.; Han, M.; Froimowicz, P. Smart and sustainable design of latent catalystcontaining benzoxazine-bio-resins and application studies. Green Chem. 2020, 22, 1209-1219. [CrossRef]

6. Pakkethati, K.; Boonmalert, A.; Chaisuwan, T.; Wongkasemjit, S. Development of polybenzoxazine membranes for ethanol-water separation via pervaporation. Desalination 2011, 267, 73-81. [CrossRef]

7. Alhwaige, A.A.; Ishida, H.; Qutubuddin, S. Carbon Aerogels with Excellent $\mathrm{CO}_{2}$ Adsorption Capacity Synthesized from Clay-Reinforced Biobased Chitosan-Polybenzoxazine Nanocomposites. Sustain. Chem. Eng. 2016, 4, 1286-1295. [CrossRef]

8. Chaisuwan, T.; Komalwanich, T.; Luangsukrerk, S.; Wongkasemjit, S. Removal of heavy metals from model wastewater by using polybenzoxazine aerogel. Desalination 2010, 256, 108-114. [CrossRef]

9. Zhou, C.; Lin, J.; Lu, X.; Xin, Z. Enhanced corrosion resistance of polybenzoxazine coatings by epoxy incorporation. RSC Adv. 2016, 6, 28428-28434. [CrossRef]

10. Xiao, Y.; Li, L.; Zhang, S.; Feng, J.; Jiang, Y.; Feng, J. Thermal Insulation Characteristics of Polybenzoxazine Aerogels. Macromol. Sci. Eng. 2019, 304, 1900137. [CrossRef]

11. Katanyoota, P.; Chaisuwan, T.; Wongchaisuwat, A.; Wongkasemjit, S. Novel polybenzoxazine-based carbon aerogel electrode for supercapacitors. Mater. Sci. Eng. B 2010, 167, 36-42. [CrossRef]

12. Linchtenhan, J.D.; Otonari, Y.A.; Carr, M.J. Linear Hybrid Polymer Building Blocks: Methacrylate-Functionalized Polyhedral Oligomeric Silsesquioxane Monomers and Polymer. Macromolecules 1995, 28, 8435-8437. [CrossRef]

13. Haddad, T.S.; Lichtenhan, J.D. Hybrid Organic-Inorganic Thermoplastics: Styryl-Based Polyhedral Oligomeric Silsesquioxane Polymer. Macromolecules 1996, 29, 7302-7304. [CrossRef]

14. Lee, A.; Linchtenhan, J.D. Viscoelastic Responses of Polyhedral Oligosilsesquioxane Reinforced Epoxy Systems. Macromolecules 1998, 31, 4970-4974. [CrossRef]

15. Nair, C.P.R. Advances in addition-cure phenolic resins. Prog. Polym. Sci. 2004, 29, 401-498. [CrossRef]

16. Ishida, H.; Rodriguez, Y. Curing kinetics of a new benzoxazine-based phenolic resin by differential scanning calorimetry. Polymer 1995, 36, 3151-3158. [CrossRef] 
17. Ishida, H.; Allen, D.J. Physical and mechanical characterization of near-zero shrinkage polybenzoxazines. J. Polym. Sci. B 1996, 34, 1019-1030. [CrossRef]

18. Wang, C.F.; Su, Y.C.; Kuo, S.W.; Huang, C.F.; Sheen, C.Y.; Chang, F.C. Low-surface-free-energy materials based on polybenzoxazines. Angew. Chem. Int. Ed. 2006, 45, 2248-2251. [CrossRef]

19. Liao, C.S.; Wang, C.F.; Lin, H.C.; Chou, H.Y.; Chang, F.C. Fabrication of patterned superhydrophobic polybenzoxazine hybrid surfaces. Langmuir 2009, 25, 3359-3362. [CrossRef]

20. Su, W.C.; Kuo, S.W. Reversible surface properties o polybenzoxazine/silica nanocomposites thin films. J. Nanomater. 2013, 2013, 97. [CrossRef]

21. Wang, C.F.; Wang, Y.T.; Tung, P.H.; Kuo, S.W.; Lin, C.H.; Sheen, Y.C.; Chang, F.C. Stable superhydrophobic polybenzoxazine surfaces over a wide $\mathrm{pH}$ range. Langmuir 2006, 22, 8289-8292. [CrossRef] [PubMed]

22. Wang, C.F.; Chen, H.Y.; Kuo, S.W.; Lai, Y.S.; Yang, P.F. Rapid, low temperature microwave synthesis of durable, superhydrophobic carbon nanotube-polybenzoxazine nanocomposites. RSC Adv. 2013, 3, 9764-9769. [CrossRef]

23. Wang, C.F.; Chiou, S.H.; Ko, F.H.; Chou, C.T.; Lin, H.C.; Huang, C.F.; Chang, F.C. Fabrication of biomimetic super-amphiphobic surfaces through plasma modification of benzoxazine films. Macromol. Rapid. Commun. 2006, 27, 333-337. [CrossRef]

24. Wang, C.F.; Chiou, F.H.; Ko, F.H.; Chen, J.K.; Chou, C.T.; Huang, C.F.; Kuo, S.W.; Chang, F.C. Polybenzoxazine as a mold-release agent for nanoimprint lithography. Langmuir 2007, 23, 5868-5871. [CrossRef]

25. Yagci, Y.; Kiskan, B.; Ghosh, N.N. Recent Advancement on Polybenzoxazine-A newly Developed High Performance Thermoset. J. Polym. Sci. A 2009, 47, 5565-5576. [CrossRef]

26. Alhwaige, A.A.; Agag, T.; Ishida, H.; Qutubuddin, S. Biobased Chitosan/Polybenzoxazine Cross-Linked Films: Preparation in Aqueous Media and Synergistic Improvements in Thermal and Mechanical Properties. Biomacromolecules 2013, 14, 1806-1815. [CrossRef]

27. Ishida, H.; Allen, D.J. Mechanical characterization of coPolymer based on benzoxazine and epoxy. Polymer 1996, 37, 4487-4495. [CrossRef]

28. Baqar, M.; Agag, T.; Ishida, H.; Qutubuddin, S. Poly(benzoxazine-co-urethane)s: A new concept for phenolic/urethane coPolymer via one-pot method. Polymer 2011, 52, 307-317. [CrossRef]

29. Chen, K.C.; Li, H.T.; Chen, W.B.; Liao, C.H.; Sun, K.W.; Chang, F.C. Synthesis and characterization of a novel siloxane-imide-containing polybenzoxazine. Polym. Int. 2011, 60, 436-442. [CrossRef]

30. Chen, K.C.; Li, H.T.; Huang, S.C.; Chen, W.B.; Sun, K.W.; Chang, F.C. Synthesis and performance enhancement of novel polybenzoxazines with low surface free energy. Polym. Int. 2011, 60, 1089-1096. [CrossRef]

31. Kuo, S.W.; Chang, F.C. POSS related polymer nanocomposites. Prog. Polym. Sci. 2011, 36, 1649-1696. [CrossRef]

32. Laine, R.M.; Roll, M.F. Polyhedral phenylsilsesquioxanes. Macromolecules 2011, 44, 1073-1109. [CrossRef]

33. Schwab, J.J.; Lichtenhan, J.D. Polyhedral oligomeric silsesquioxane (POSS)-based Polymer. Appl. Organometal. Chem. 1998, 12, 707-713. [CrossRef]

34. Abe, Y.; Gunji, T. Oligo- and polysiloxanes. Prog. Polym. Sci. 2004, 29, 149-182. [CrossRef]

35. Leu, C.M.; Chang, Y.T.; Wei, K.H. Polyimide-Side-Chain Tethered Polyhedral Oligomeric Silsesquioxane Nanocomposites for Low-Dielectric Film Applications. Chem. Mater. 2003, 15, 3721-3727. [CrossRef]

36. Seino, M.; Hayakawa, T.; Ishida, Y.; Kakimoto, M.; Watanabe, K.; Okikawa, H. Hydrosilylation Polymerization of Double-Decker-Shaped Silsesquioxane Having Hydrosilane with Diynes. Macromolecules 2006, 39, 3473-3475. [CrossRef]

37. Sodkhomkhum, R.; Ervithayasuporn, V. Synthesis of poly(siloxane/double-decker silsesquioxane) via dehydrocarbonative condensation reaction and its functionalization. Polymer 2016, 86, 113-119. [CrossRef]

38. Liao, Y.T.; Lin, Y.C.; Kuo, S.W. Highly Thermally Stable, Transparent, and Flexible Polybenzoxazine Nanocomposites by Combination of Double-Decker-Shaped Polyhedral Silsesquioxanes and Polydimethylsiloxane. Macromolecules 2017, 50, 5739-5747. [CrossRef]

39. Wei, K.; Wang, L.; Zheng, S. Organic-inorganic coPolymer with double-decker silsesquioxane in the main chains by polymerization via click chemistry. J. Polym. Sci. A Polym. Chem. 2013, 51, 4221-4232. [CrossRef]

40. Wang, L.; Zhang, C.; Zheng, S. Organic-inorganic poly(hydroxyether of bisphenol A) coPolymer with double-decker silsesquioxane in the main chains. J. Mater. Chem. 2011, 21, 19344-19352. [CrossRef] 
41. Wu, S.; Hayakawa, T.; Kikuchi, R.; Grunzinger, S.J.; Kakimoto, M.; Oikawa, H. Synthesis and Characterization of Semiaromatic Polyimides Containing POSS in Main Chain Derived from Double-Decker-Shaped Silsesquioxane. Macromolecules 2007, 40, 5698-5705. [CrossRef]

42. Huang, J.C.; He, C.B.; Xiao, Y.; Mya, K.Y.; Dai, J.; Siow, Y.P. Polyimide/POSS nanocomposites: Interfacial interaction, thermal properties and mechanical properties. Polymer 2003, 44, 4491-4499. [CrossRef]

43. Teo, J.K.H.; Teo, K.C.; Pan, B.; Xiao, Y.; Lu, X. Epoxy/polyhedral oligomeric silsesquioxane (POSS) hybrid networks cured with an anhydride: Cure kinetics and thermal properties. Polymer 2007, 48, 5671-5680.

44. Liu, N.; Li, L.; Wang, L.; Zheng, S. Organic-inorganic polybenzoxazine coPolymer with double decker silsesquioxanes in the main chains: Synthesis and thermally activated ring-opening polymerization behavior. Polymer 2017, 109, 254-265. [CrossRef]

45. Lee, Y.J.; Huang, J.M.; Kuo, S.W.; Chen, J.K.; Chang, F.C. Synthesis and characterizations of a vinyl-terminated benzoxazine monomer and its blending with polyhedral oligomeric silsesquioxane (POSS). Polymer 2005, 46, 2320-2330. [CrossRef]

46. Lee, Y.J.; Kuo, S.W.; Huang, C.F.; Chang, F.C. Synthesis and characterization of polybenzoxazine networks nanocomposites containing multifunctional polyhedral oligomeric silsesquioxane (POSS). Polymer 2006, 4, 4378-4386. [CrossRef]

47. Kimura, H.; Matsumoto, A.; Hasegawa, K.; Ohtsuka, K.; Fukuda, A. Epoxy resin cured by bisphenol A based benzoxazine. J. Appl. Polym. Sci. 1998, 68, 1903-1910. [CrossRef]

48. Choi, J.; Kim, S.G.; Laine, R.M. Organic/Inorganic Hybrid Epoxy Nanocomposites from Aminophenylsilsesquioxanes. Macromolecule 2004, 37, 99-109. [CrossRef]

49. Xiao, F.; Sun, Y.; Xiu, Y.; Wong, C.P. Preparation, thermal and mechanical properties of POSS epoxy hybrid composites. J. Appl. Polym. Sci. 2007, 104, 2113-2121. [CrossRef]

Publisher's Note: MDPI stays neutral with regard to jurisdictional claims in published maps and institutional affiliations. 